\title{
La emergencia de las sociedades obesogénicas o la obesidad como problema social (I+Dः CSO2009- 07683)
}

Mabel Gracia Arnaiz

Este trabajo ilustra que las actuales concepciones de la comida y el cuerpo, y las prácticas sociales en las que ambos intervienen, están relacionadas con los procesos de medicalización, mercantilización e individualización que han acontecido en las sociedades modernas de forma intensa en las últimas décadas. Estos tres procesos se han concretado en torno a lo que aquí denominamos la normativización dietética y corporal, un fenómeno que permite comprender por qué el dieting — estar o ponerse a dieta—, la salud y, en definitiva, el cuidado de uno mismo alcanzan un papel tan central en la vida cotidiana y por qué se relacionan directamente con la emergencia de enfermedades como la obesidad.

Hemos analizado el proceso que va de la lipofobia - el rechazo a las grasas o a engordar generalizado en el s. xx - al lipofobismo - el trato discriminatorio recibido por las personas gordas por su peso/gordura-. Nuestra tesis es que la medicalización de la obesidad, lejos de contribuir a desestigmatizar a las personas obesas, se convierte en una vía para (re)significar negativamente la gordura. En este sentido, la ambivalencia acompaña la definición de la obesidad en cuanto enfermedad y la de las personas obesas en cuanto enfermas. Si desde la concepción biomédica los gordos son víctimas de una sociedad consumista y permisiva y, por lo tanto, se convierten en enfermos, también son identificados como personas que transgreden los modelos normativos - la dieta óptima y el ejercicio físico regular-. Así, si bien es cierto que el concepto de enfermedad suele implicar una exculpación de los pacientes respecto de su estado patológico, en el caso de la obesidad este requisito no se cumple necesariamente ya que se considera que la gordura es, en parte, autoinfligida, y ello contribuye a no exculpar a las víctimas.

Hemos visto que las representaciones y experiencias en torno a la corporalidad no son iguales para todos ni permanecen igual a lo largo de los itinerarios biográficos. La edad y el género se convierten en condicionantes relevantes y ambas variables afectan a las trayectorias vitales. Si la negatividad atribuida al 
estar gordo se vive incómodamente desde la primera socialización, durante la adolescencia se acentúa. El cuerpo, en proceso de rápida y a menudo involuntaria transformación, adquiere un papel determinante en las relaciones interpersonales y en la construcción de la identidad. Efectivamente, el aspecto físico juega un papel importante en los itinerarios de los jóvenes, y el aumento de peso o la acumulación desigual o desproporcionada de la grasa son vividos con profundo malestar. A medida que las formas corporales se alejan de los patrones estándares, las recriminaciones se activan en los diferentes espacios relacionales y dificultan las relaciones interpersonales. La desviación de la norma favorece la propia desvalorización subjetiva, de tal manera que la estigmatización de la obesidad se convierte en un verdadero círculo vicioso: la víctima acepta y considera normales las incriminaciones recibidas e inicia una depreciación personal que afecta negativamente a la imagen de sí misma. En las mujeres esta estigmatización es aún más punzante porque, además de ser más criticable, a menudo aparece vinculada con itinerarios donde la precarización es frecuente.

La discriminación es expresada como un hecho constante y sistemático en los diferentes ámbitos — educativo, laboral, familiar, ocio y tiempo libre - en el que transcurre la vida. La ropa, los asientos de los transportes o lugares públicos, ir a la playa o a las clases de educación física en las escuelas y los institutos son objetos o situaciones críticos que recuerdan que, a diferencia de otras enfermedades, esta no se puede disimular ni esconder. La obesidad siempre es visible. Todos, hombres y mujeres de todas las edades, se han sentido avergonzados de su cuerpo frente a los otros y ellos mismos. Sin embargo, la preocupación más importante se da entre las chicas, ya que en la delgadez femenina se sintetizan razones de estética, clase social y disciplina mucho más exigentes. Los chicos y las chicas más jóvenes consideran que la adolescencia es el período más vulnerable al ridículo que acompaña la obesidad. Los adultos, sin embargo, tienden a relacionar la gordura excesiva con la salud, lo que no significa olvidar la relevancia de la estética.

Mientras que en otros países se han puesto en marcha movimientos alternativos de contestación (pro-fat, fat acceptance, fat is beautiful, etc.), en nuestro país esto no ha sucedido. Hemos podido comprobar que la gente diagnosticada de obesidad incorpora el discurso médico hegemónico, de forma que acepta su estado corporal como un estado insalubre o poco saludable y busca soluciones para evitarlo. Los informantes no se han adherido a los movimientos de acep- 
tación de la gordura, salvo para reivindicar su condición de persona y evitar las diversas formas de discriminación vividas. Para conseguir perder el exceso de peso, los informantes inician diversos procesos de control de peso (seguimiento de dietas, cirugía, fármacos) que a menudo terminan en fracaso y en una ganancia de kilos, lo que provoca historias de frustraciones y sufrimiento que duran toda la vida.

Finalmente, mostramos que las medidas adoptadas para cambiar las causas atribuidas al incremento de la obesidad ("estilos de vida poco saludables") se centran antes en la responsabilización individual y la educación nutricional que en la modificación de los factores estructurales que la motivan. Se evidencia que, si bien hay unanimidad en el diagnóstico, este es insuficiente porque no explica cómo los mudables modos de vida afectan, de forma compleja, a las maneras de comer y estas a la salud de los distintos grupos sociales. El análisis de las iniciativas y los programas de prevención elaborados en diferentes países (España y México) muestra la estandarización de las estrategias internacionales frente a la obesidad y sirve para reflexionar sobre los efectos de manejar una visión limitada de la cultura y la alimentación. En España las acciones emprendidas son múltiples y a menudo se centran en el corto plazo, aunque con diferentes grados de implantación según la comunidad autonómica estudiada (Cataluña y Murcia) y al margen de la mayor o menor prevalencia de la obesidad. Se constata una notable descoordinación entre sí y una falta de instrumentos para la evaluación de los programas, aspectos que supuestamente mejorarán tras la aprobación de la Ley de Seguridad Alimentaria y Nutrición (2011). Hasta la fecha, sin embargo, las recomendaciones y acciones continúan siendo homogéneas en cuanto al contenido, se dirigen al gran público y no tienen en cuenta que la obesidad no afecta a todo el mundo por igual. Los resultados de este trabajo apuntan a una clara feminización de la obesidad, vinculada en mayor medida a mujeres adultas en situación de precarización. 